\title{
Dental Expert System
}

\author{
Oladele Tinuke $\mathrm{O}$. \\ Dept. of Computer Science, \\ University of llorin \\ Ilorin, Nigeria
}

\author{
Sanni Yetunde \\ Dept. of Computer Science, \\ University of llorin \\ llorin, Nigeria
}

\begin{abstract}
The early 20th century brought along a better understanding of dental disease and prevention. However, advancement in computer technology has encouraged researchers to develop software for assisting doctors in making decision without consulting the specialists directly. Software development exploits the potential of human intelligence such as reasoning, making decision, learning by experience and many others. The software was not meant to replace the specialist or doctor, yet it was developed to assist general practitioners and specialist in diagnosing and predicting patient's condition from certain rules or experience. The goal of this paper is to demonstrate the practical applicability of Information and Communication Technology (ICT) for the diagnosis of dental ailments based on a set of symptoms.
\end{abstract}

Expert system is a computer system that emulates the decision-making ability of a human expert. Expert system in medical applications reduces cost, time, human expertise and medical error. This paper on Dental Expert System is a desktop based application designed to replace the manual system used by most Medical organizations in treatment. This paper is aimed at emphasizing on the use of expert systems to diagnose mild dental problems.

In this paper, the ED Expert System which is referred to as Electronic Dentist was developed based on the Coactive Neuro-Fuzzy Expert System Model and implemented by using C\# programming language. The expert system is a simple and user friendly desktop application which could be used by anyone so as to complement the manual process of diagnosis.

\section{General Terms}

Symptoms, Artificial Intelligence, Neural Network.

\section{Keywords}

Expert System, Dentist, Patient, Dental Diseases, Fuzzy Logic.

\section{INTRODUCTION}

Expert Systems are computer programs that are derived from a branch of computer science research called Artificial Intelligence (AI). The term intelligence covers many cognitive skills, including the ability to solve problems, learn, and understand language. AI's scientific goal is to understand intelligence by building computer programs that exhibit intelligent behavior. It is concerned with the concepts and methods of symbolic inference, or reasoning, by a computer, and how the knowledge is used to make those inferences will be represented inside the machine. Expert systems are knowledge-based computer programs designed to provide assistance in diagnosis and treatment planning. They assist the practitioner in decision making.
For the first time the computers have been used in the dental medicine in the 1960s. Since then computers and information technologies spread progressively in the dental practice. According to Atkinson, J. in the year of 2000, 85 which is about $1 \%$ of all dentists in the United States use computers [1].

A search of the literature on expert system design for medical and dental applications was carried out. It showed an increase in the number of articles on this subject. Between 1984 and 1991, 608 articles have been published in medical journals and two in dental journals. Because it is likely that this development will influence dental practice in the future a critical review of medical literature on the topic has also been carried out. A number of general principles are described to give the dental practitioner some insight into how expert systems work. A set of criteria have been formulated from the medical literature which expert systems should meet. These requirements are also applicable to dentistry and may be used to judge dental expert systems.

The use of computers to assist health professionals in their activities has been studied since the 1950s. Initial work was focused on the development of diagnostic systems. Ledley (a dentist) and Lusted were the first to address this possibility [2]. They described the use of punch cards for indicating relationships between diseases and their manifestations. An experimental prototype was described in a later publication. Problems including the limitations of the scientific foundation and the resistance by practitioners to accept a system that was not integrated into their usual workflow prevented the widespread establishment of the system.

Since then, researchers have applied different methods to provide clinical applications with knowledge. More recent work on Dental expert system has focused on integration of these applications with clinical databases. These integrated systems take advantage of data already recorded for other purposes in order to avoid redundant data entry in the provision of alerts and reminders. Research has also been done on eliciting patients' preferences for therapeutic options, which can help health care professionals to gain a better understanding of aspects of these options that are important from the patient's perspectives. A typical example is a system that checks for drug-drug interactions or possible patient allergy to a medication when a provider is writing a prescription. In asynchronous mode, Dental expert system performs their reasoning independently of any users awaiting its output. An example is the generation of a reminder for an annual visit for checkup and hygiene.

In this paper, the developed Expert System is called ED which means Electronic Dentist and it was developed based on the combination of two artificial intelligence techniques known as Artificial Neural Networks and Fuzzy Logic. The application was implemented using C\# (C Sharp) programming language. 


\section{RELATED WORK}

Dentistry is involved in the study, diagnosis, prevention, and treatment of diseases, disorders and conditions of the teeth such as oral cavity, maxillofacial area and the adjacent and associated structures and their impact on the human body. Dentistry is widely considered necessary for complete overall health. Doctors who practice dentistry are known as dentists. The dentist's supporting team which includes dental assistants, dental hygienists, dental technicians, and dental therapists aid in providing oral health services.

\subsection{Evolution of Artificial Intelligence in Medical Application}

Artificial Intelligence (AI) is a study to emulate human intelligence in computer technology. The potential of AI in medicine has been expressed by a number of researchers. Hoong summarized the potential of AI techniques in medicine as follows [3]:

i. Provides a laboratory for the examination, organization, representation and cataloguing of medical knowledge,

ii. Produces new tools to support medical decision-making, training and research,

iii. Integrates activities in medical, computer, cognitive and other sciences, and

iv. Offers a content-rich discipline for future scientific medical specialty.

Computer program known as Medical Decision-Support System was designed to help health professionals make clinical decision [4]. The system deals with medical data and knowledge domain in diagnosing patients' conditions as well as recommending suitable treatments for the particular patients. Patient-Centered Health Information Systems is a patient centered medical information system developed to assist in monitoring, managing and interpreting patient's medical history [5]. In addition the system provides assistance to patients and medical practitioners. The system serves to improve the quality of medical decision-making, increases patient compliance and minimizes medical errors.

The advancement in computer technology and communication encourages health-care providers to provide health-care over the Internet or telemedicine [6]. Rusovick and Warner defined telemedicine as any instance of medical care occurring via the Internet and using real-time videoteleconferencing equipment as well as more specialized medical diagnostic equipment [7]. In general, telemedicine means the use of computer and communications technologies to augment the delivery of health-care services [8]. Telemedicine can improve access to care, increase health-care quality and reduce the cost [9]. The approach reduces the cost and time for both patients and doctors.

ICT based diagnosis of malaria and some other diseases have been reported in the literature. In the paper, a fuzzy expert system for the management of malaria [10], fuzzy logic was used. Online system for diagnosis and treatment of malaria was reported in Donfack et al where a rule based expert system was designed with the possibility of interacting with the system in real time and through mobile devices based on global system for mobile communication (GSM) technology [11].
A medical expert system for managing tropical diseases was proposed by [12]. In the proposed Medical Expert System (MES), the inference engine uses a forward chaining mechanism to search the knowledge-base for symptoms of a disease and its associate therapy which matches the query supplied by the patient.

Obot and Uzoka designed a fuzzy rule based framework for the management of tropical diseases [13]. Fuzzy logic was applied to determine the degree of severity of tropical diseases. In fuzzy expert system for the management of hypertension [14], a fuzzy expert system was used to diagnose hypertension.

In another study on a decision support system for tuberculosis diagnosis also reported in a decision support system based on fuzzy logic was used in the diagnosis of tuberculosis [15]. Application of neuro-fuzzy expert system for the probe and prognosis of thyroid disorder was reported in [16], where a hybrid neuro-fuzzy expert system was used in the diagnosis of thyroid disorder. This hybrid system is not adaptive in nature. Hence, it can only serve for cases that have been predefined in the knowledge base.

\subsection{An Overview of Dental Expert System}

Dental Expert System is a health-related expert system that is based on the diagnosis and treatment of dental problems. It includes complication of the disease condition if it persists, and possible prevention of diseases.

\subsubsection{The Traditional System}

This system is what has being in use in Nigerian Clinics, Hospitals and Medical organizations up to the time of writing this paper despite the revolution in information technology. Studies have shown that every patient has to go through the manual method which involves having a direct contact with the Doctors on duty before treatment can be administered. In this system, each patient undergoes the stress of meeting the receptionists to acquire his/her card by a registered index number. The receptionists will then manually trace the patient's card through the index number before it is being transferred to the Doctor's desk. In this system, the dentists analyze the patient symptoms based on his/her medical knowledge and experience to reach a conclusion of the ailment the patient is suffering from. In some cases, the dentist will have to carry out a practical examination.

\subsection{Neuro-Fuzzy Modeling}

The synergy of two intelligent techniques such as neural network and fuzzy logic form the basis of Neuro-fuzzy modeling.

\subsubsection{Fuzzy Inference Systems (FIS)}

The fuzzy inference system is a popular computing framework based on the concepts of fuzzy set theory, fuzzy ifthen rules and fuzzy reasoning. It has been applied in variety of fields such as automatic control, data classification, decision analysis, expert systems, time series prediction, robotics and pattern recognition. Because of its multidisciplinary nature, the fuzzy inference system is known by numerous other names, such as fuzzy rule-based system, fuzzy expert system [17], fuzzy model [18], [19], fuzzy associative memory [20], fuzzy logic controller [21], [22], [23], and fuzzy system. Figure 1 shows the block diagram of the Fuzzy Inference System (FIS). 


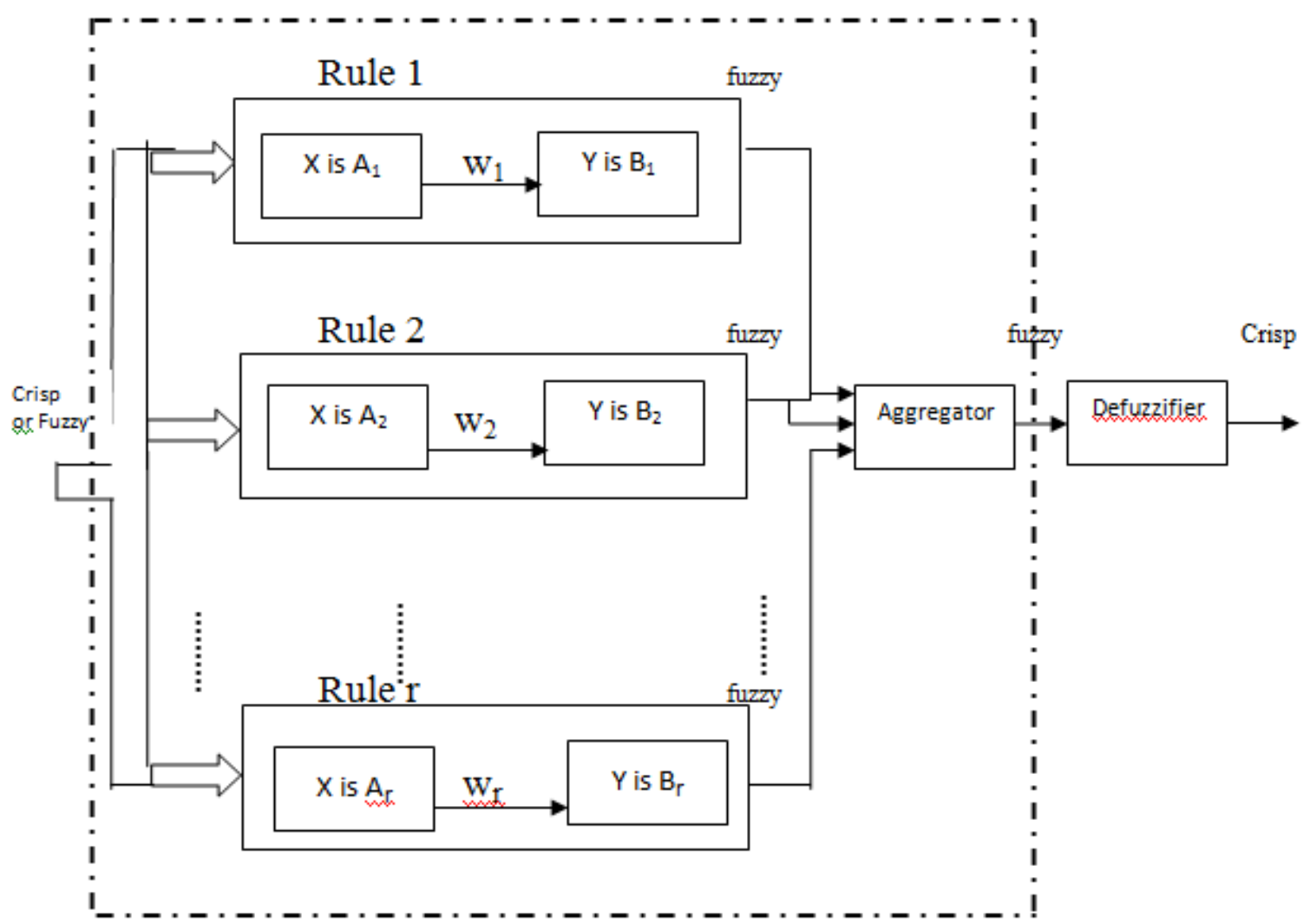

Figure 1: Block diagram for a Fuzzy Inference System with Rule Aggregator.

\subsubsection{Adaptive Network-Based Fuzzy Inference} System (ANFIS)

A class of adaptive networks that act as a fundamental framework for adaptive fuzzy inference systems is referred to as ANFIS. ANFIS stands for Adaptive Network-Based Fuzzy Inference System or Adaptive Neuro-Fuzzy Inference System [24], [25], [26]. The ANFIS model is given in Figure 2.

\section{Layer 1}

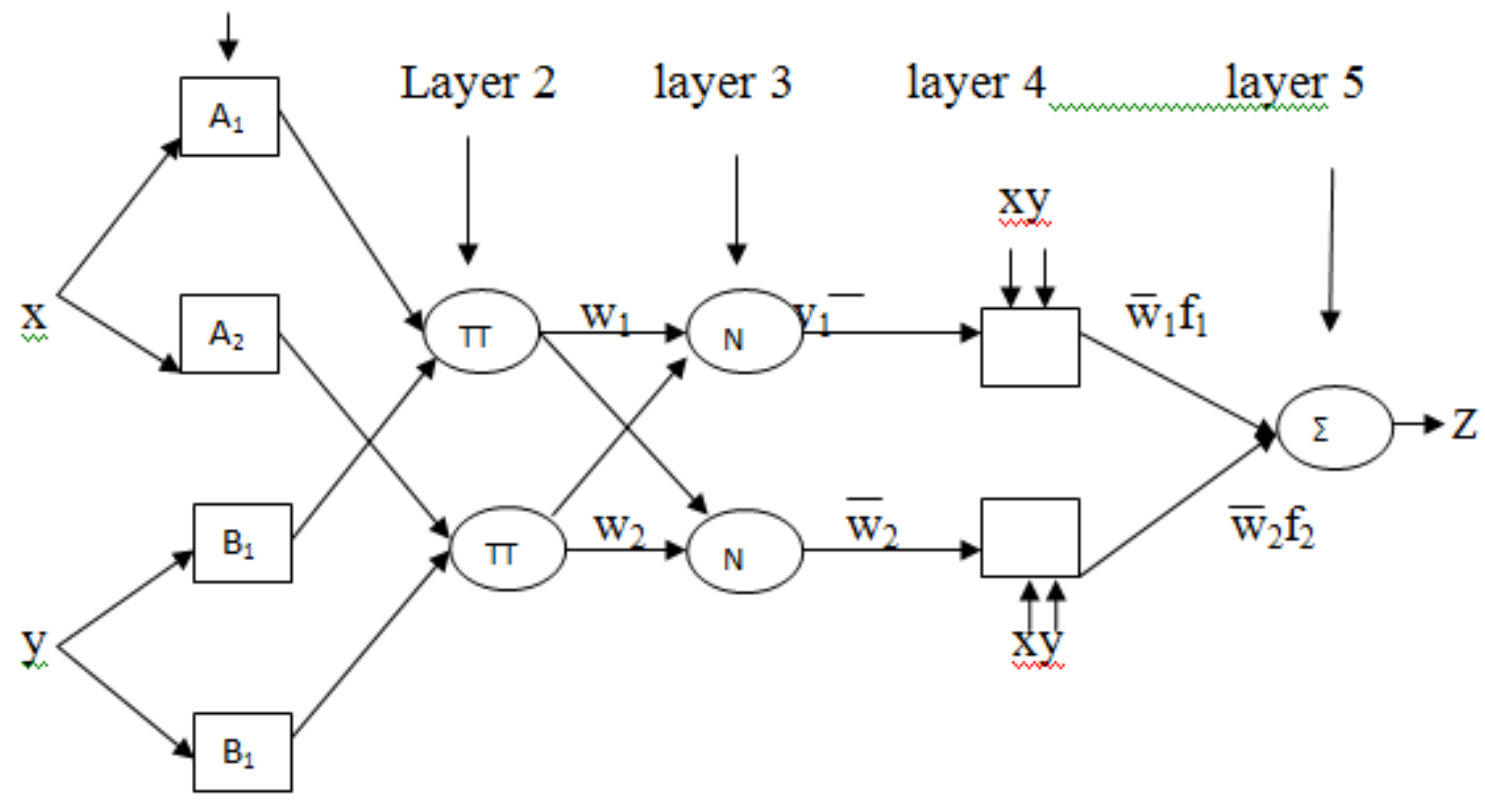

Figure 2: ANFIS Model 
In this paper, the fuzzy inference system under consideration has two inputs $\mathrm{x}$ and $\mathrm{y}$ and output $\mathrm{z}$ for a first-order Sugeno fuzzy model as suggested by Sugeno et al, and Tagaki et al, [18], [19]. A typical rule set with two fuzzy if then rules can be expressed as:

Rule 1: If $x$ is $A_{1}$ and $y$ is $B_{1}$, then $f_{1}=p_{1} x+q_{1} y+r_{1}$,

Rule 2: If $x$ is $A_{2}$ and $y$ is $B_{2}$, then $f_{2}=p_{2} x+q_{2} y+r_{2}$

where $\mathrm{p}_{1}, \mathrm{q}_{1}$, and $\mathrm{r}_{1}$ are the consequent parameters of Rule 1 and $\mathrm{p}_{2}, \mathrm{q}_{2}$, and $\mathrm{r}_{2}$ are the consequent parameters of Rule 2 , while $\mathrm{f}_{1}$ and $\mathrm{f}_{2}$ are node functions for Rules 1 and 2 respectively. As illustrated in figure 2, a square node (adaptive node) has parameters while a circle node (fixed node) has no parameter.

Layer 1: Calculates membership value for premise parameter.

Every node $\mathrm{i}$ in this layer is an adaptive node with a node output defined by

Output $\mathrm{O}_{1, \mathrm{i}}$ for node $\mathrm{i}=1,2$ is given by $\mathrm{O}_{1, \mathrm{i}}=\mu_{\mathrm{Ai}}(\mathrm{x})$, or

Output $\mathrm{O}_{1}$, for node $\mathrm{i}=3,4$ is given by $\mathrm{O}_{1}, \mathrm{i}=\mu_{\mathrm{Bi}-2}(\mathrm{y})$

Where $\mathrm{x}$ (or $\mathrm{y}$ ) is the input to the node and $\mathrm{A}_{\mathrm{i}}\left(\right.$ or $\left.\mathrm{B}_{\mathrm{i}-2}\right)$ is a fuzzy set associated with this node. Hence, outputs of this layer are the membership values of the premise part. The membership functions of $A_{i}$ and $B_{i}$ can be any appropriate parameterized membership function. For example, $A_{i}$ can be characterized by the generalized bell function:

$$
\mu \mathrm{A}_{\mathrm{i}}(\mathrm{x})=\frac{1}{1+\frac{\left[\left(\mathrm{x}-\mathrm{c}_{\mathrm{i}}\right)^{2}\right]^{\mathrm{bi}}}{\mathrm{a}_{\mathrm{i}}}}
$$

Where $\mathrm{A}$ is a linguistic label such as mild, moderate, severe and very severe, and $\left(\mathrm{a}_{\mathrm{i}}, \mathrm{b}_{\mathrm{i}}\right.$ and $\left.\mathrm{c}_{\mathrm{i}}\right)$ are the parameter set. Parameters in this layer are referred to as premise parameters. The node output is the membership value of the input.

Layer 2: Every node in this layer is a fixed node labeled TT (T-norm), which multiples the incoming signals and outputs the product. For instance,

$\mathrm{O}_{2, \mathrm{i}}=\mathrm{w}_{\mathrm{i}}=\mu_{\mathrm{Ai}}(\mathrm{x}) \mathrm{x} \mu_{\mathrm{Bi}}(\mathrm{y}), \quad$ for $\mathrm{i}=1,2$

Each node output represents the firing strength of a rule.
Layer 3: Every node in this layer is a fixed node labeled N. The ith node calculates the ratio of the ith rule's firing strengths:

$$
\mathrm{O}_{3, \mathrm{i}}=\overline{\mathrm{w}}_{\mathrm{i}}=\frac{\mathrm{w}_{\mathrm{i}}}{\mathrm{w}_{1}+\mathrm{w}_{2}} \quad \text { for } \mathrm{i}=1,2
$$

Outputs of this layer are called normalized firing strengths.

Layer 4: Every node $i$ in this layer is an adaptive node with a node function.

$$
\mathrm{O}_{4, \mathrm{i}}=\mathrm{w}_{\mathrm{i}} \mathrm{f}_{\mathrm{i}}=\mathrm{w}_{\mathrm{i}}\left(\mathrm{p}_{\mathrm{i}} \mathrm{x}+\mathrm{q}_{\mathrm{i}} \mathrm{y}+\mathrm{r}_{\mathrm{i}}\right)
$$

Where $\bar{w}_{i}$ is the output of layer 3 and $\left(p_{i}, q_{i}, r_{i}\right)$ is the parameter set. Parameters in this layer are referred to as consequent parameters.

Layer 5: The single node in this layer is a fixed node labeled $\sum$, which computes the overall output as the summation of all incoming signals:

$$
\mathrm{O}_{5, \mathrm{i}}=\text { overall output }=\sum \mathrm{w}_{\mathrm{i}} \mathrm{f}_{\mathrm{i}}=\frac{\sum_{\mathrm{i}} \mathrm{w}_{\mathrm{i}} \mathrm{f}_{\mathrm{i}}}{\sum_{\mathrm{i}} \mathrm{w}_{\mathrm{i}}}
$$

The output is linear in consequent parameter.

\subsubsection{Coactive Neuro-Fuzzy Inference System (CANFIS)}

ANFIS has made its mark as an adaptive system with much emphasis on its capability of being a linguistically interpretable fuzzy Inference System (FIS) that allows prior knowledge to be embedded into its construction and allows the possibility of understanding the results of learning. A generalized ANFIS which emphasize characteristics of a more fused neuro-fuzzy system that enjoys many of the advantages claimed for Neural Networks (NNs) and the linguistic interpretability of a FIS, is known as CANFIS. CANFIS stands for Coactive Neuro-fuzzy Inference System.

The application of back propagation algorithms to fuzzy systems in a network layered presentation spurred the development of neuro-fuzzy modeling [24], [27], [28]. A single output CANFIS can be illustrated in the same schematic diagram of ANFIS as shown in Figure 3. 


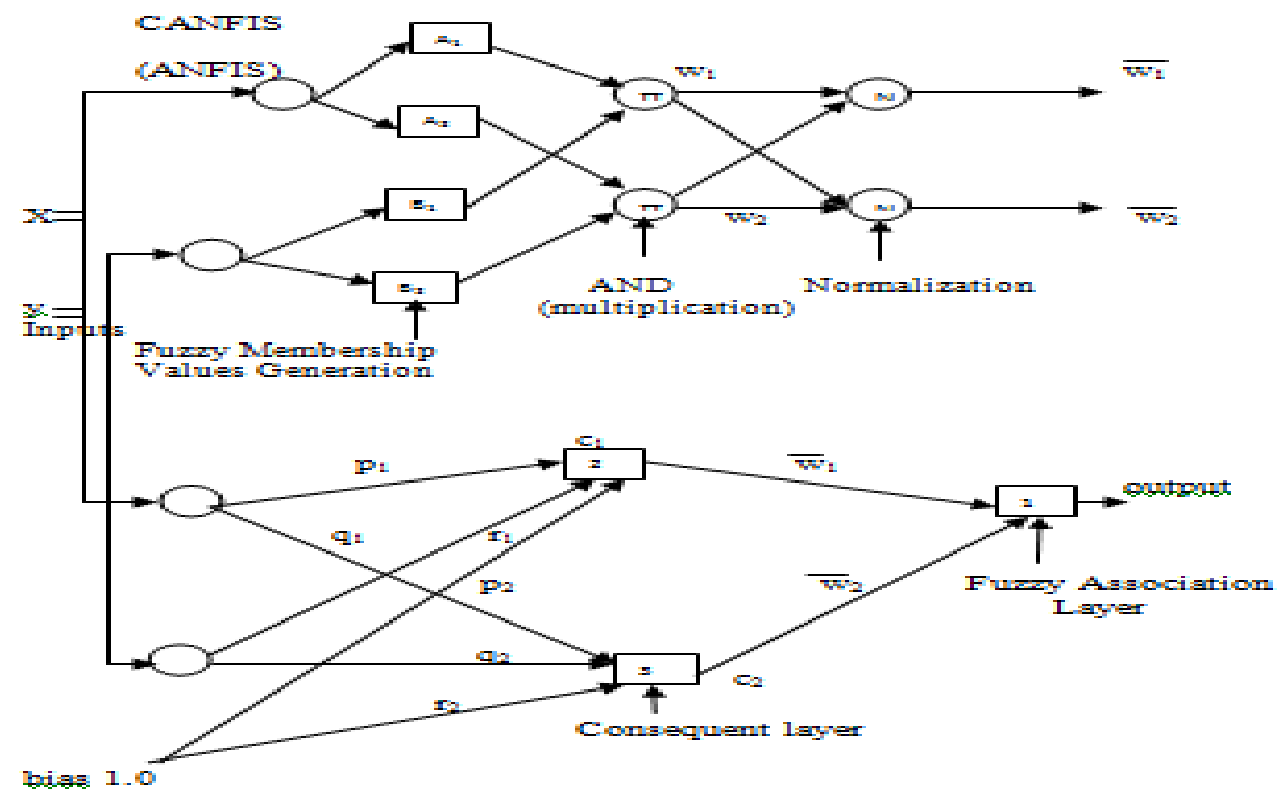

Figure 3: CANFIS Model

where,

$\mathrm{C}_{1}=\mathrm{f}_{2}\left(\mathrm{p}_{1} \mathrm{x}+\mathrm{q}_{1} \mathrm{y}+\mathrm{r}_{1}\right)$

$\mathrm{C}_{2}=\mathrm{f}_{3}\left(\mathrm{p}_{2} \mathrm{x}+\mathrm{q}_{2} \mathrm{y}+\mathrm{r}_{2}\right)$

When all the three neurons (1, 2, and 3) have identity functions, the presented CANFIS is equivalent to the Sugeno Fuzzy Inference System [19], which accomplishes fuzzy if then rules (linear rules) such as the following:

Rule 1: if $x$ is $A_{1}$ and $y$ is $B_{1}$ then $C_{1}=p_{1} x+q y+r_{1}$

Rule 2: if $\mathrm{x}$ is $\mathrm{A}_{2}$ and $\mathrm{y}$ is $\mathrm{B}_{2}$ then $\mathrm{C}_{2}=\mathrm{p}_{1} \mathrm{x}+\mathrm{q}_{2} \mathrm{y}+\mathrm{r}_{2}$

In this study, the CANFES model was adopted from CANFIS. While CANFIS is specific to controllers, CANFES is best suited for domains where human experts have to make decisions in real time.

\subsubsection{The Coactive Neuro-Fuzzy Expert System (CANFES) Model}

The motivation for approximating fuzzy systems by neural networks is based upon the inherent capability of neural networks to perform massive parallel processing of information. This is important in the fuzzy controllers or more generally fuzzy expert systems that are required to process large numbers of fuzzy inference rules in real time. When the neural network representing a given fuzzy expert system is implemented all relevant fuzzy inference rules are processed in parallel. This results in high computational efficiency, which is crucial in many applications such as diagnosis, prediction and so on.

Moreover, the neural network representation is eminently fitted for introducing suitable adaptive capabilities into the system. This is due to the inherent learning capabilities of neural networks which can be used for modifying fuzzy inference rules of the system on the basis of experience. Learning ability is another strength of neural networks. Among the three classes of learning schemes as reported in [29], the unsupervised procedures which construct internal models that capture regularities in their input vectors without receiving any additional information [30], are suitable to find clusters of data indicating the presence of fuzzy rules. The supervised procedures which require a teacher to specify the desired output vector, and the reinforcement procedures which only require a single scalar evaluation of the output are good to adapt the ruling of membership functions for the desired output in fuzzy logic systems.

Hence, a hybrid learning algorithm is being used for the CANFES model. The learning algorithm for this model combines unsupervised learning and supervised learning procedures to build the rule nodes and train the membership functions. The hybrid learning algorithm performs superiorly to the purely supervised learning algorithm such as, back propagation or learning algorithm [31], due to the prior classification of training data through an overlapping receptive field before the supervised learning.

The learning rate of the original back propagation learning algorithm is limited by the fact that all layers of weights in the network are determined by the minimization of an error signal which is specified only as a function of the output, and a substantial fraction of the learning time is spent in the discovery of internal representation. This observation was also reported in the two papers [32], [33]. The hybrid learning rule being used for the CANFES model combines both the back propagation (BP) and Kohonen Self Organizing Features Map (KSOFM). While BP is a supervised learning algorithm, KSOFM is an unsupervised learning algorithm.

The CANFES model also maintains the concept of human thinking and reasoning as in fuzzy inference systems. So, experts' knowledge can easily be incorporated into the structure. The CANFES structure also saves the rule-matching time of the inference engine in the traditional fuzzy inference system.

It has been found in the literature that previous studies on medical diagnosis were based mainly on fuzzy expert systems. Some of the demerits of fuzzy logic control or fuzzy 
expert systems have been highlighted in the literature review. It has been deduced that a combination of both neural network and fuzzy inference systems or fuzzy expert systems form a better adaptive model which has the capability to learn from experience and handle new situations that have not been predefined in the knowledge base as a human expert will do.

In view of the foregoing, the CANFES model is being applied to the diagnosis of dental ailments. CANFES is the acronym for Coactive Neuro-Fuzzy Expert System [34]. A synergism between neural networks and fuzzy expert system will give a better model and software that can perform as well as a human expert, such as physician in the area of medical diagnosis of diseases. The CANFES model is shown in figure 4 (a). The architecture of the back propagation learning rule is shown in Figure 4 (b).

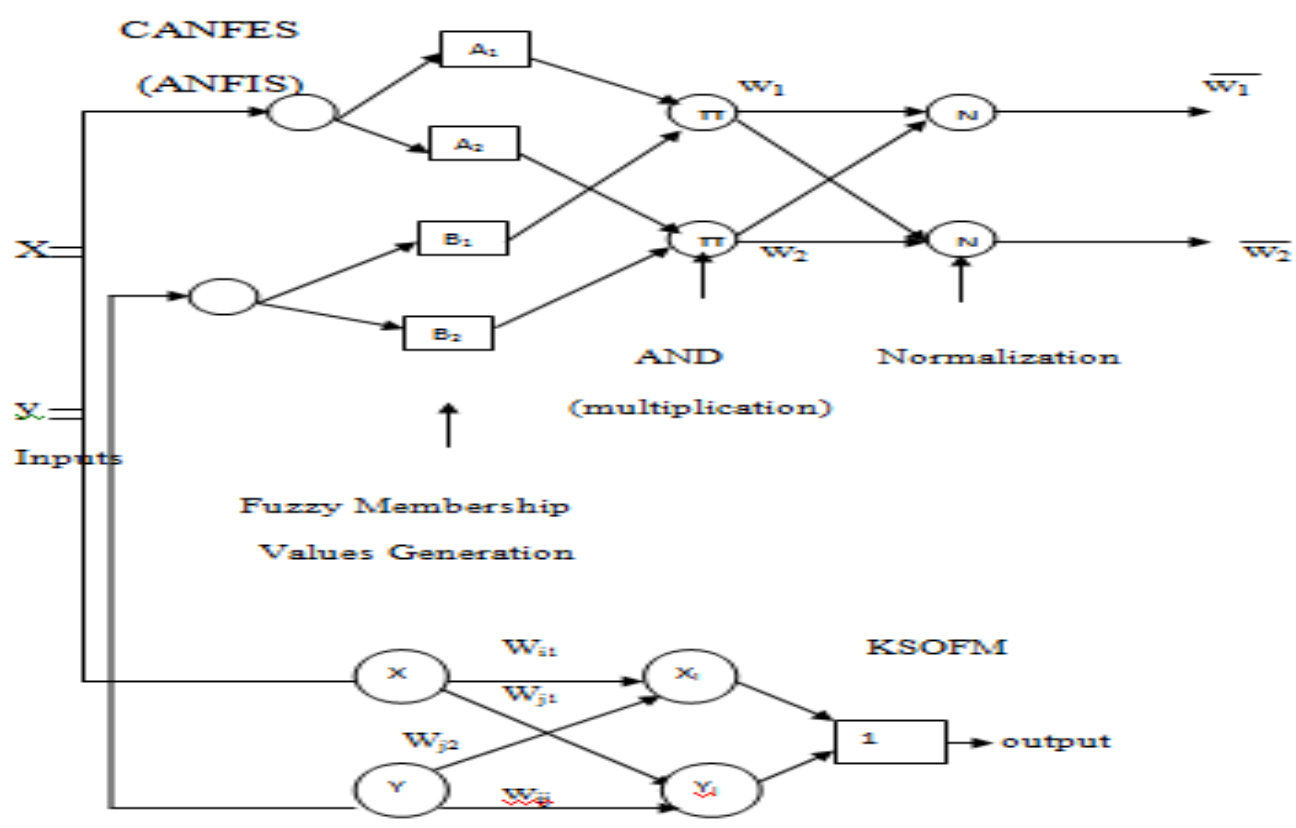

Figure 4 (a): The CANFES Model

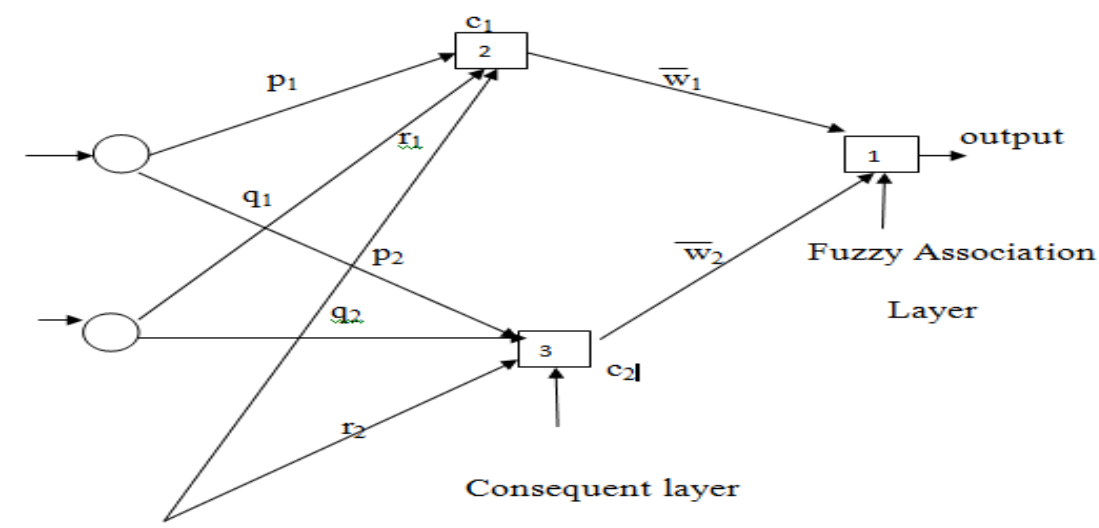

bias 1.0

Figure 4 (b): Architecture of the Back Propagation Network

\section{Architectural Framework for the CANFES}

\section{Model}

An architectural framework was developed for the CANFES model. The architectural framework is shown in Figure 5.
This framework captures all the features and components that are involved in the entire Coactive Neuro-Fuzzy Expert System model [34]. 


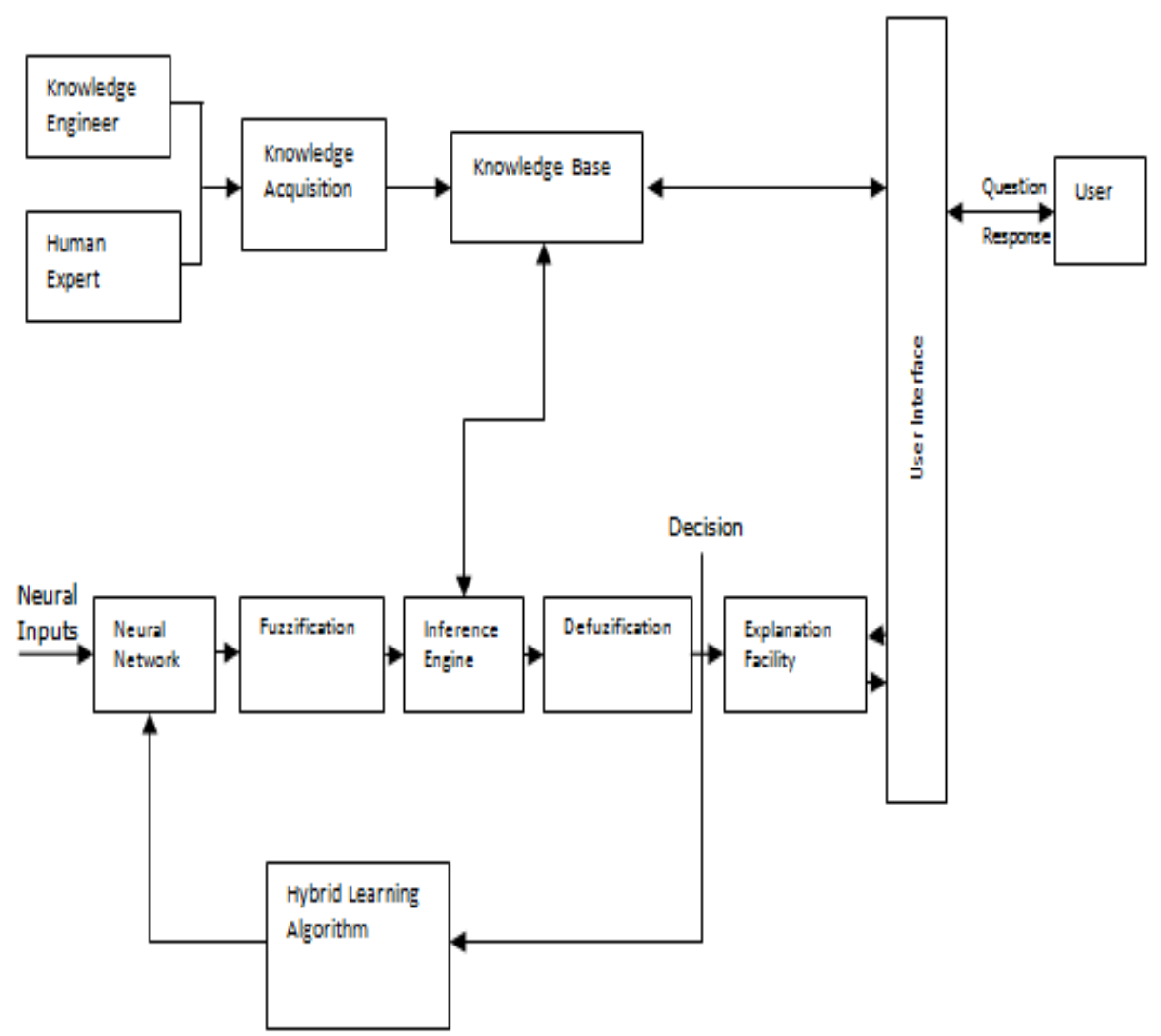

Figure 5: Architectural Framework for the CANFES Model

\subsection{Limitations of the Traditional System}

i. It is usually time consuming and stressful for both the Medical practitioners and patients.

ii. Incompetency of the dentist in charge can lead to wrong treatment.

iii. The whole system is usually inaccurate.

iv. The patients have to get to the dentist before getting the proper treatment

\subsection{Benefits of the Electronic System}

The electronic based system is used in some medical organizations abroad. The benefits of the electronic records would be many, namely to enhance traditional records, fast storage and retrieval, promote telemedicine and encourage research in medical applications. This paper presents a desktop-based medical expert system for diagnosis and prediction of dental diseases. The Dental Expert System is an open loop system which will be handled by Medical Practitioners in the Dental field who selects the symptoms of the patient and the expert system work on these symptoms based on symbolic rules to arrive at the best ailment together with the cause, prevention, and diagnosis. Another significance of this expert system is that it will also serve as a management system to keep past and existing records of patient's data.

\section{METHODOLOGY}

The application was developed with the intention of solving real life problems, therefore the latest technologies were used

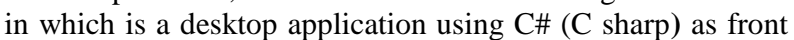

end and Microsoft SQL as database to ensure efficiency, reliability and maximum security since the users will be limited.

\subsection{Analysis of the Proposed System}

Having known the problems encountered in the existing system, the new system has been able to solve the problems to the minimum level so as to make the system viable and efficient enough to meet the needs of the users and in the management of the new system which is the Dental expert System. In this system, the nurse or receptionists will register the information of every patient in a management system, each nurse also have access to the use the expert system to treat a patient but should in case the dentist is not around, the patient will be referred to meet the dentist for diagnosis and treatment. In this case, the dentists also have an access to the patient management system and will be the one to use the expert system for proper treatment based on the patient's symptoms.

This system starts with a page where users are given the opportunity to enter their login details such as the Username (which is the name the administrator use in registering a user) and Password (also created by the administrator) for easy usage of the system by registering so as to be able to log into the system at anytime. This system consists of several interactive pages.

This system has four phases:

1. An administrator's role

i. Can create new user account and assign/change (of an existing user) username and password. 
ii. Can configure the symptom and ailment.

2. A medical director's role

i. Configure the symptom and ailment.

ii. Use the edExpert system.

3. A dentist's role

i. Use the edExpert system for administering treatment.

ii. Can also manage the patient records.

4. A nurse/receptionist

The nurse and receptionist have the same interface and role because nurses also perform the duties of the receptionists in most health centers.

i. Expert system for administering treatment in case the dentist is not around in extreme cases.

ii. Manage the patient records.

\subsection{Analysis of the Dental Expert System using the Canfes Model}

\subsubsection{Symptoms of Dental Diseases}

Symptoms of Dental Diseases include: toothache, pain with chewing, headache, sensitivity of the teeth, tooth discoloration, redness or swelling of the gums, receding or bleeding gums, worn-down teeth, broken or chipped teeth, loose or lost, fever, earache, or pain when opening your mouth wide, brushing discomfort, burning sensation, itching of the ear, mouth sores, pain in the gum, pain in the neck area, and bad breath and so on.

Dental symptoms are commonly caused by tooth decay, infection, inflammation or injury; however, malnutrition, certain types of cancer, and inherited disorders can also cause these symptoms.

\subsubsection{Neuro-Fuzzy Expert System}

Neural Network

Neural networks are composed of simple elements operating in parallel. These elements are inspired by the biological nervous system. A neural network can be trained to perform a particular function by adjusting the values of the connections (weights) between the elements. Essentially, neural networks are adjusted, or trained, so that a particular input leads to a specific target output. Figure 6 illustrates such a situation. Here, the network is trained (adjusted) based on a comparison of the output and the target, until the network output matches the target. Typically, many suc 1 inpgeterget pairs are needed to train a network.

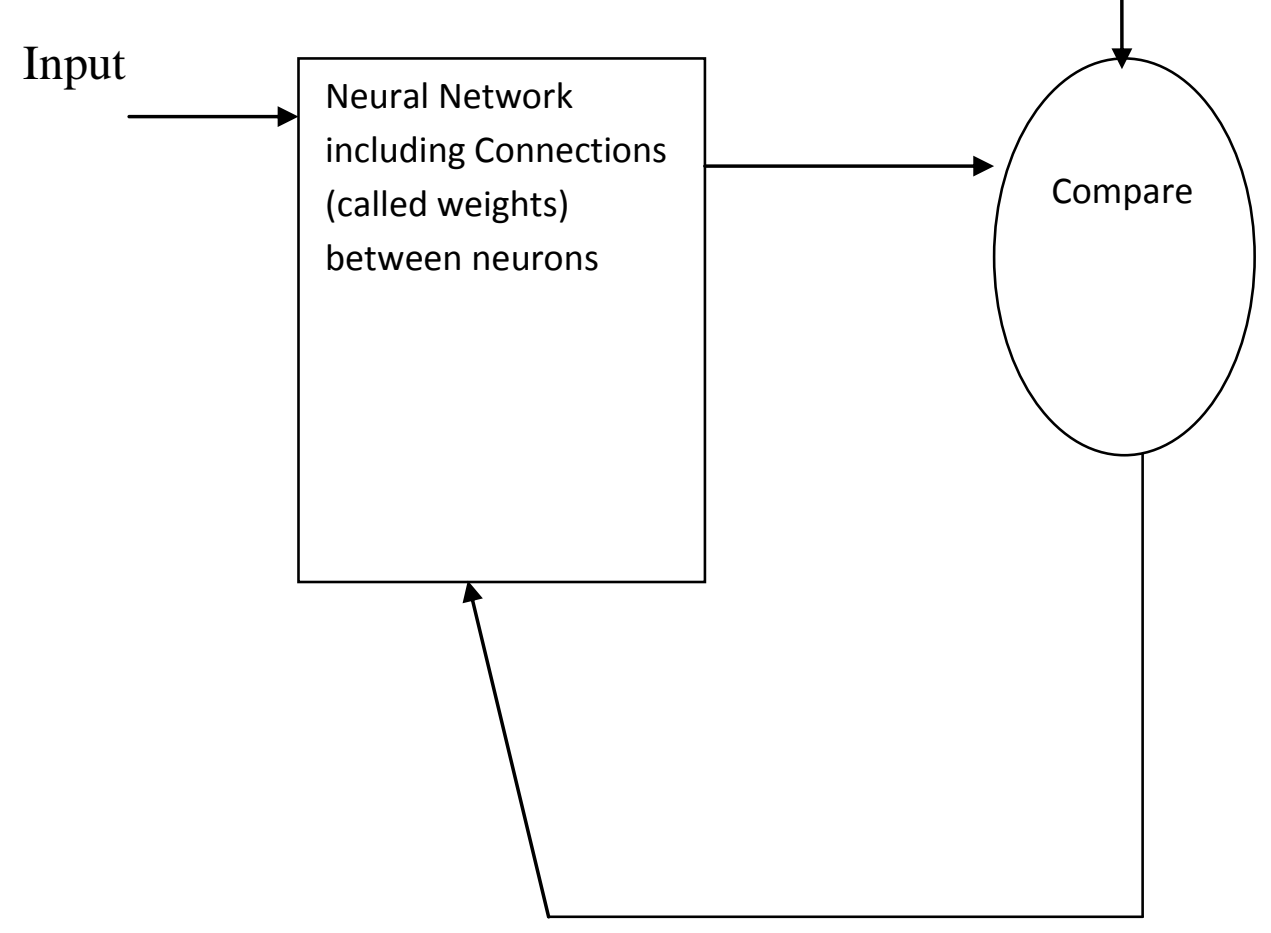

Figure 6: Neural Network Training Procedure

\section{Fuzzy Logic}

\section{(a) Fuzzy Sets}

A classical set is a set which is defined by crisp (exact) boundaries. For example, a set of even numbers. $A=\{2,4,6$, $8,10\}$. Here there is a clear and unambiguous boundary. Hence, a non even number does not belong to the set.

In contrast to a classical set, a fuzzy set is a set without a crisp (sharp or clear) boundary. It also allows partial membership.
That is, the transition from "belonging to a set" to "not belonging to a set" is gradual and this smooth transition is characterized by membership functions that give fuzzy sets the flexibility in modeling commonly used linguistic expressions, such as "the body is warm" or "the temperature is high". As Zadeh [35] pointed out in the seminar paper entitled "Fuzzy Sets", such imprecisely defined sets or classes play an important role in human thinking. Fuzziness comes 
from the uncertain and imprecise nature of the linguistics expressions.

\section{(b) Fuzzy Sets and Membership Functions}

A fuzzy set A in the universe of discourse $U$ can be defined as a set of ordered pairs and it is given by

$$
\mathrm{A}=\left\{\mathrm{x}, \mu_{\mathrm{A}}(\mathrm{x}) \mid \mathrm{x} \epsilon \mathrm{U}\right\}
$$

where $\mu_{A}(x)$ is called the membership function (MF) of $x$ in $\mathrm{A}$, and it indicates the degree that $\mathrm{x}$ belongs to $\mathrm{A}$. The degree of membership $\mu_{\mathrm{A}}(\mathrm{x})$ assumes values in the range from 0 to 1 . That is, membership function (MF) maps each element of $U$ to a continuous membership value (or membership grade) between 0 and 1 . Fuzzy sets are the tools that convert the concept of fuzzy logic into algorithms. Fuzzy sets can be thought as a medium through which the human thinking is transferred to a computer. Membership function defines the fuzziness in a fuzzy set irrespective of the elements in the set, which are discrete or continuous. Membership functions are generally represented in graphical form. The rules that define fuzziness graphically are also fuzzy. MF maps each elements of $U$ to a membership grade between 0 and 1 by using various shapes such as triangular membership function, trapezoidal membership function, sigmoidal membership function and Gaussian membership function.

Hence,

$\mu_{\mathrm{A}}(\mathrm{x})=1$ If $\mathrm{x}$ is totally in $\mathrm{A}$

$\mu_{\mathrm{A}}(\mathrm{x})=0$ If $\mathrm{x}$ is not in $\mathrm{A}$

$$
\mathrm{O}<\mu_{\mathrm{A}}(\mathrm{x})<1 \quad \text { If } \mathrm{x} \text { is partially in } \mathrm{A}
$$

Equation 1, with value 1 corresponds to absolute membership. The value 0 as shown in equation 2 corresponds to absolute non-membership. The value between 0 and 1 , as shown in equation 3 correspond to partial membership. Triangular membership function which is widely used was used in the development of the proposed expert system.

\subsubsection{Neuro-Fuzzy Measures for Diagnosis}

This section states the algorithmic steps that are needed for the ICT based diagnosis.

\section{Pseudocode for Neuro-Fuzzy Diagnosis}

Step 1: Capture patients personal information into the database

Step 2: Input signs and symptoms of patient's complaint into the system

Step 3: Assign fuzzy values to variables identified to be causative symptoms

Step 4: Search the knowledge base for the signs and symptoms identified

Step 5: Get the associated degree of intensity; that is, mild, moderate, severe and very severe.

Step 6:

$$
\text { Apply fuzzy rules }
$$

Step 7: Map fuzzy inputs into their respective weighing factors to determine their degree of membership.

Step 8: Use neural network to represent the membership functions

Step 9: Train the neural network

Step 10: Determine the rule base evaluation
Step 11: Determine the firing strength of the rules

Step 12: Calculate the degree of truth of each of the rules by evaluating the non-zero minimum value

Step 13: Compute the intensity of the disease

Step 14: Output neuro-fuzzy diagnosis

\section{Fuzzzification}

Fuzzification is the process of changing crisp values into fuzzy values. This can be achieved with the aid of different types of fuzzifiers. This is the process of transforming a crisp set to a fuzzy set or a fuzzy set to a fuzzier set. That is, crisp quantities are converted to fuzzy quantities and vice versa.

Based on the domain expert's knowledge, both the input and output parameters selected were described with four linguistic variables (mild, moderate, severe, and very severe). The range of fuzzy values for each linguistic variable is shown in table 1 .

Table 1: Range of Fuzzy Values

\begin{tabular}{|l|l|}
\hline Linguistic Variables & Fuzzy Values \\
\hline Mild & $0.1 \leq \mathrm{x} \leq 0.3$ \\
\hline Moderate & $0.3 \leq \mathrm{x} \leq 0.6$ \\
\hline Severe & $0.6 \leq \mathrm{x} \leq 0.8$ \\
\hline Very severe & $0.8 \leq \mathrm{x} \leq 1.0$ \\
\hline
\end{tabular}

Fuzzification begins with the transformation of the raw data by using the membership functions. During the fuzzification process, linguistic variables are evaluated using triangular membership function and are accompanied by associated degree of membership ranging from 0 to 1 .

\section{Inference}

The process of drawing conclusion from existing data is called inference. Fuzzy inference is the process of mapping from a given input to an output using the theory of fuzzy sets. The core of decision making is done in the inference engine by using the rules contained in the rule base. The inference engine uses the rules in the knowledge base and derives conclusions based on the rules. The Dental Expert System inference engine uses a forward chaining mechanism to search the knowledge base for the symptoms of the disease. For each rule, the inference mechanism looks up to the membership values in the condition of the rule. Fuzzy inputs are mapped out in their respective weighting factors and their associated linguistics variables to determine their degree of membership. The membership functions are then trained in order to adjust the weight to the desired target output.

A rule is said to fire if any of the precedence parameters (mild, moderate, severe, very severe) evaluate to true (1); otherwise, if all the parameters evaluate to false (0), it does not fire. 


\section{Defuzzification}

The defuzzification process translates the output from the inference engine into crisp output. This is due to the fact that, the output from the inference engine is usually fuzzy while crisp values are required for most expert systems and medical applications. Many defuzzfication techniques are proposed in the literature and some common ones are: center of gravity, center of sums, weighted average method, maximum membership principle and so on. The center of gravity is the most widely used techniques because when it is used, the defuzzified values tend to move smoothly around the fuzzy output regions. Hence, it is also used in this study.

As shown in Figure 5, the Knowledge Engineer and Human Expert (Domain Expert) have long sessions of dialogue in order to elicit knowledge for the expert system. The result of the communication and dialogue between the knowledge engineer and domain expert establishes the knowledge acquisition module. The acquired knowledge is then deposited into the knowledge base.
Neural inputs which are numerical in nature are entered into the neural network for processing. The presence of a symptom is represented by 1 and the absence of a symptom is represented by 0 . These constitute the input into the neural network. The neural output is then fuzzified into fuzzy values which are linguistic in nature before entering the inference engine where decisions (such as diagnosis) are made. If the output from the inference engine does not conform to the target output or does not precisely give the diagnosis, then hybrid learning rule is being applied to train the neural network and the input data is reprocessed by adjusting weights (training) before it is being sent back to the inference engine. The inference engine communicates with the knowledge base in order to apply appropriate rules for decision making. The output from the inference engine (decision) is then sent into an explanation facility where the actual result or output will be interpreted to the user. The user interacts with the expert system by asking questions or performing queries, and the expert system gives its response according to the decision made in the inference engine.

\section{STAGE ONE}

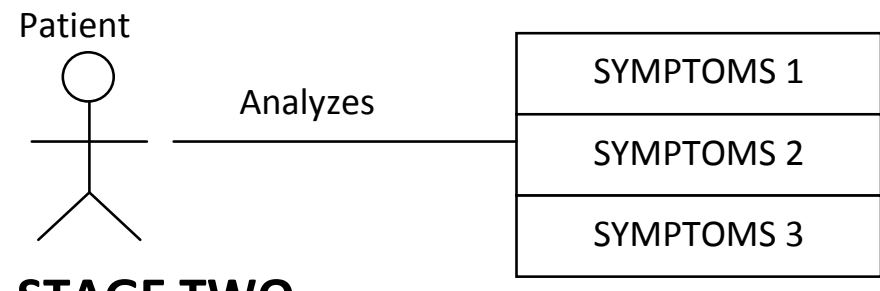

\section{STAGE TWO}

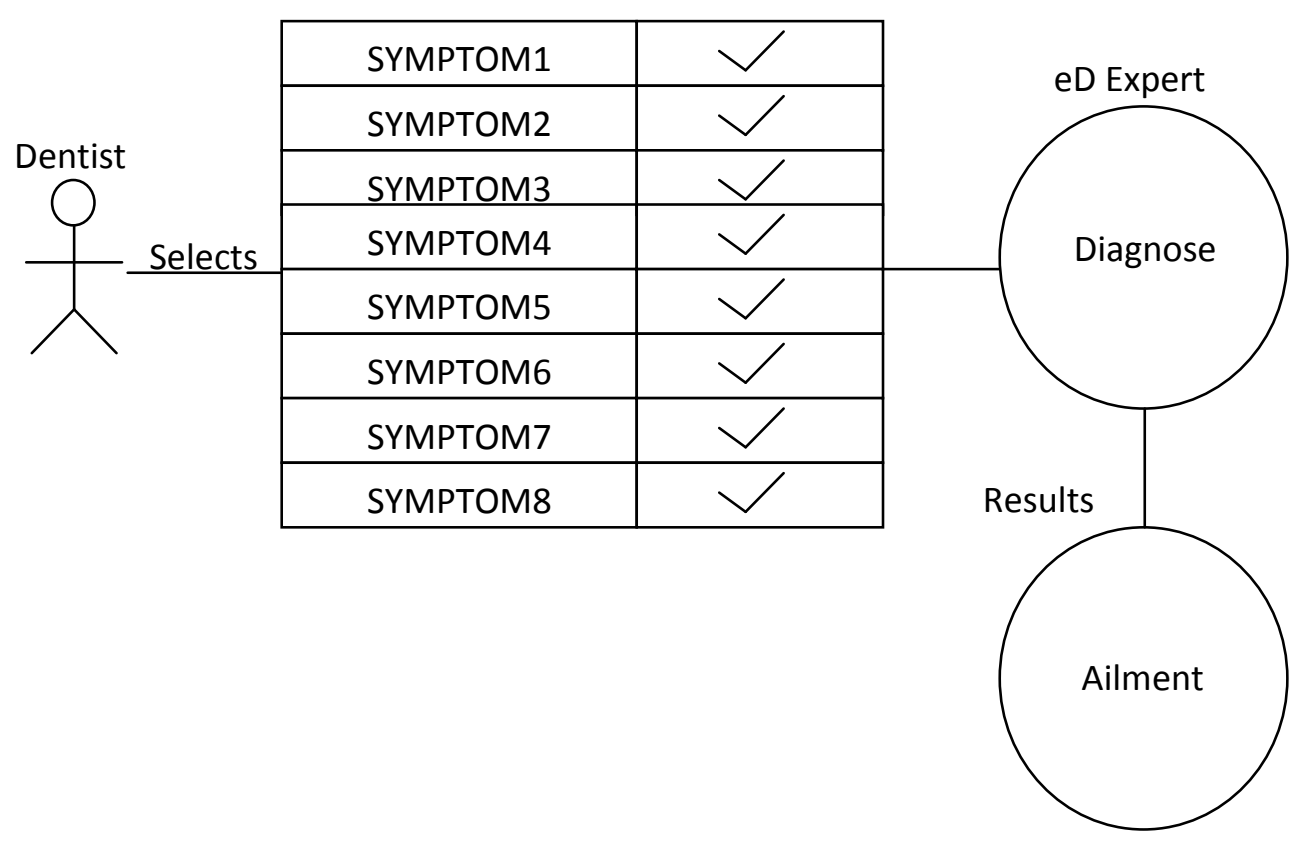

Figure 7: Case Diagram for eD Expert System

\section{RESULTS}

The User Login Page is the authentication which is used to capture the username and password. Figure 8 shows the authentication page. This page is to regulate unauthorized access to the application. 


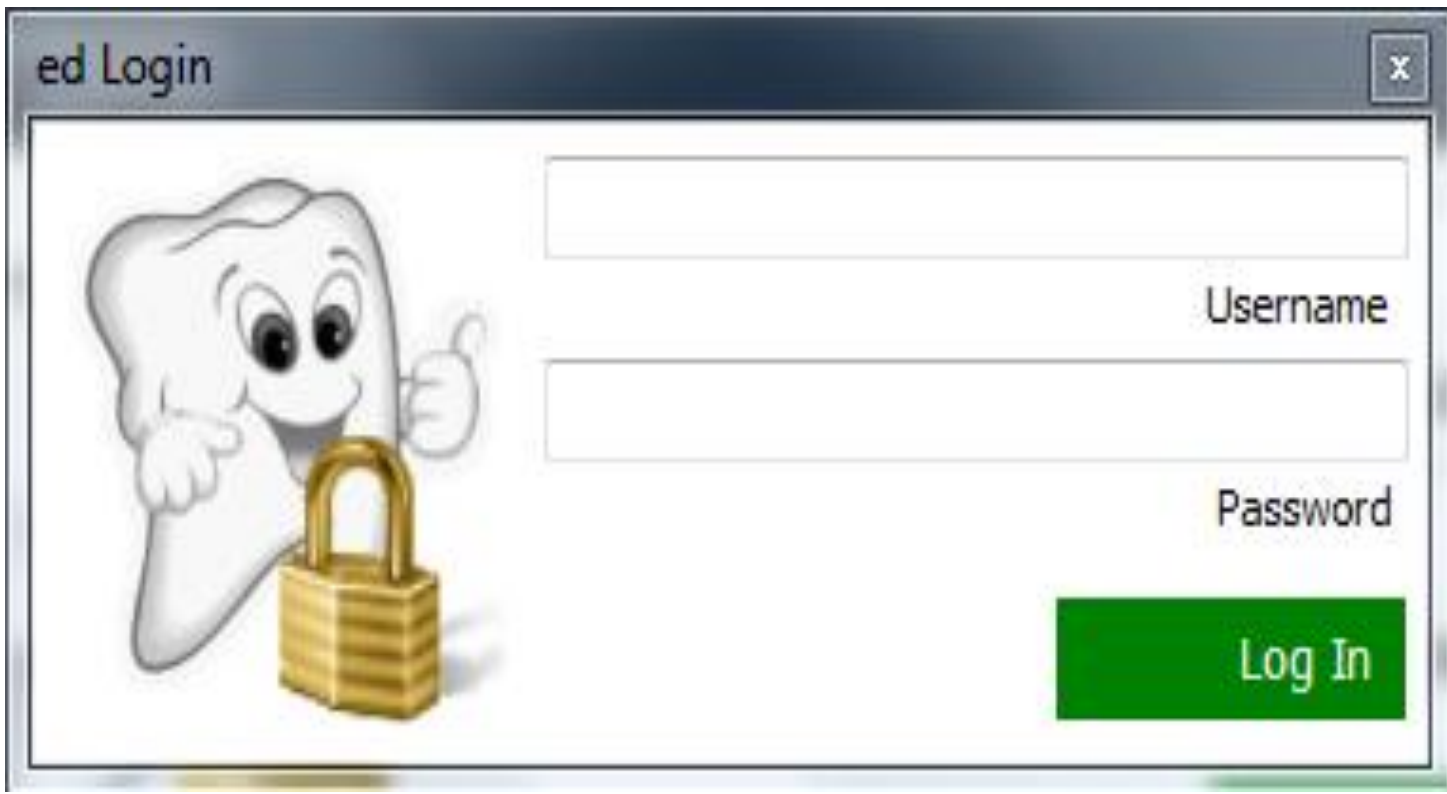

Figure 8: User Login Page

The system administrator page consists of the main menu of the application. It serves as the link to all the other modules in the application. Figure 9 shows the System Administrator Page.

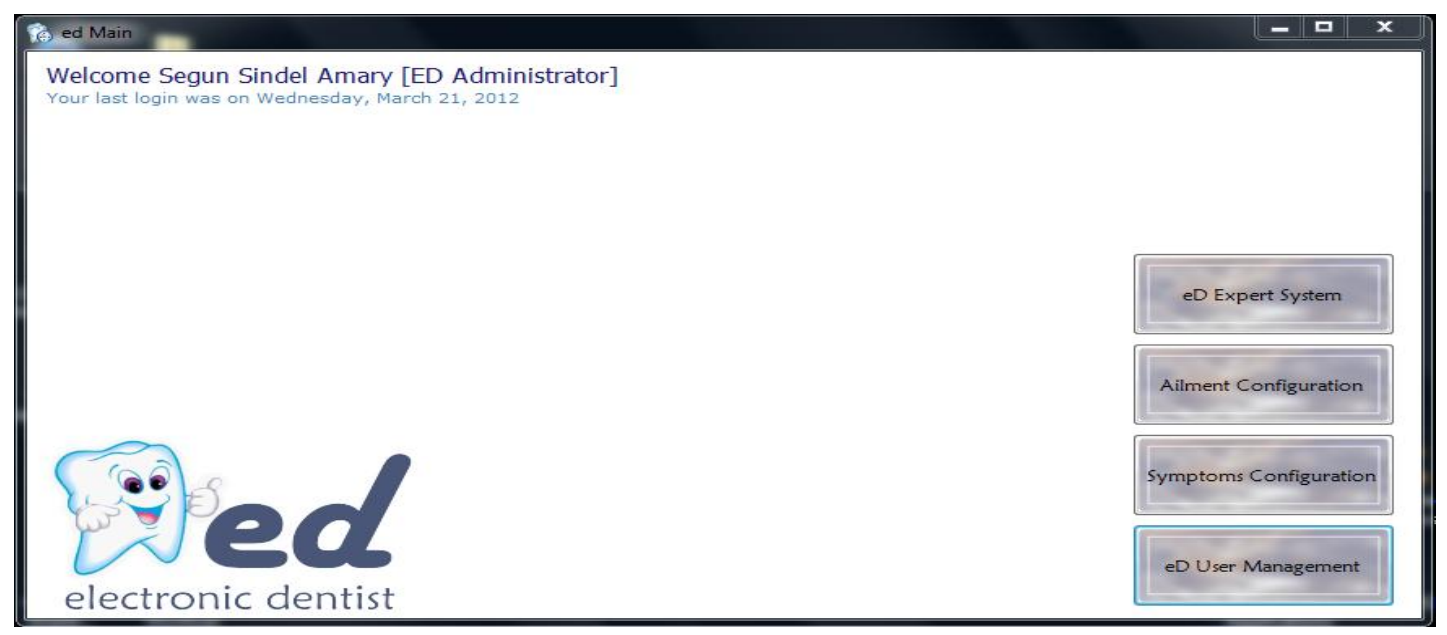

Figure 9: System Administrator Page

The eD Expert System module displays the list of all available symptoms and allows the patient's symptoms to be selected as shown in Figure 10 which is the Expert System module whose diagnosis is made. Diagnosis is made with respect to the chosen symptoms. A list of ailments which matches the symptoms are then given on which the dentist draws inference based on a set of rules in order to diagnose a particular ailment for patients respectively. 


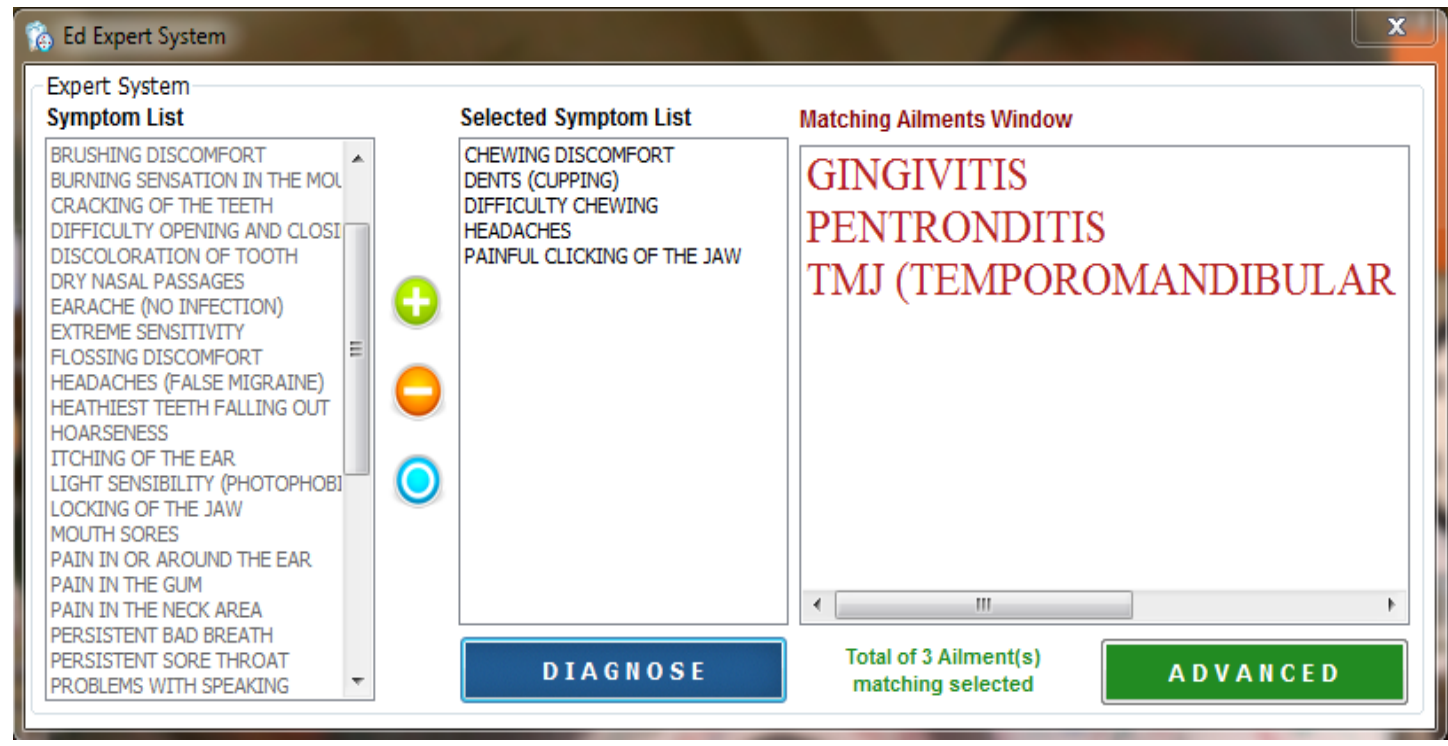

Figure 10: eD Expert System

Decision for treatment is made after diagnosing a particular ailment as shown in Figure 11.

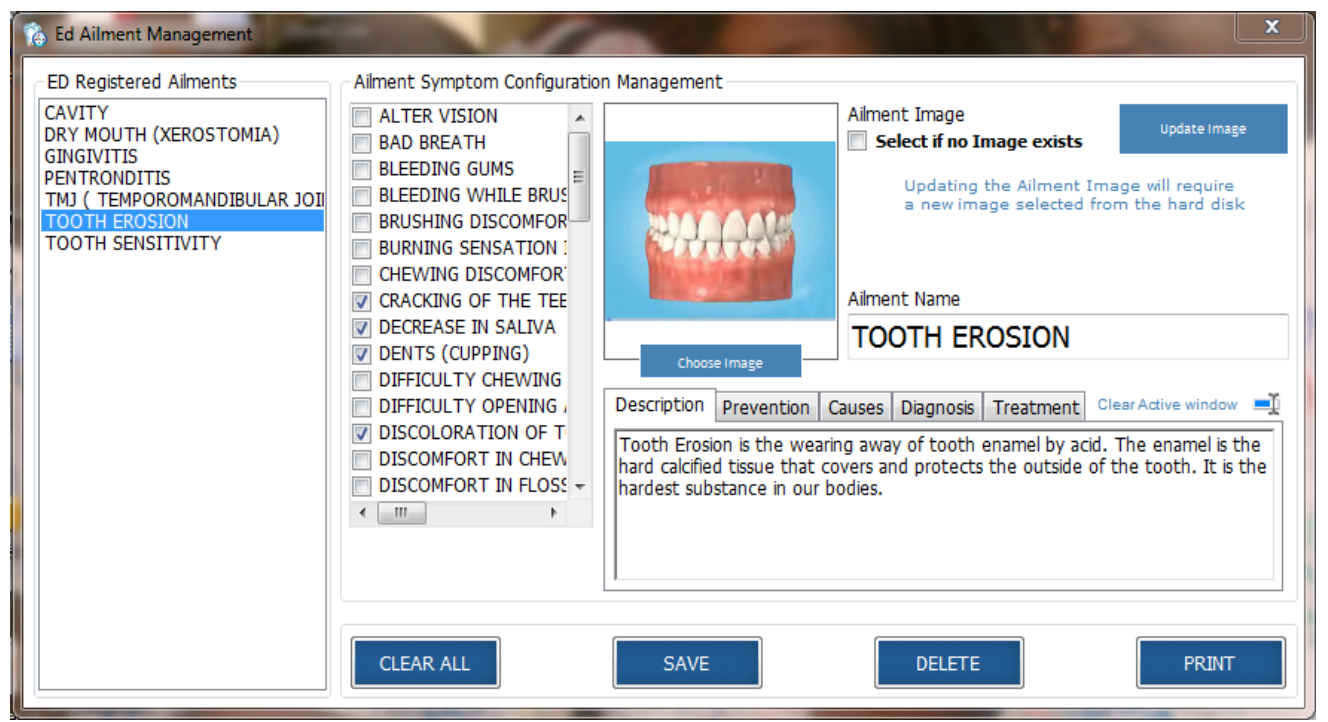

Figure 11: Symptoms Configuration

\section{CONCLUSION}

The Dental expert system has been able to show that automating the management and administration of treatment is more reliable and efficient than the manual approach of the existing system. In this paper, the ICT based eD Expert System was developed using the Coactive Neuro-Fuzzy Expert System Model. Speed and Accuracy is achieved in the computerized system which will prevent mix up or confusion in the documentation of patients' information. It reduces the stress involved in treatment administration to patients considering the tight schedule of most medical practitioners. The reliability and efficiency of the developed system is also higher than that of the existing system. Updating and maintenance of the program can be done easily. It is interactive and easy to use. The eD Expert System has taken care of the lapses in the existing manual system to a great extent and has designed a more efficient, accurate and speedy method of preparing enrollment report.

\section{REFERENCES}

[1] Atkinson, J. et al. (2002), Electronic patient records for dental school clinics: more than paperless systems. Journal of Dental Education, 66, Vol. 5, 634 - 642.

[2] Ledley, R. S. and Lusted, L. B. (1959). "Reasoning Foundations of Medical Diagnosis". Science 130: 9-21. Doi: 10.1126/science.130.3366.9. JSTOR 1758070. 
[3] Hoong, N. K. (1988). Medical Information Science Framework and Potential. In Proceedings of the International Seminar and Exhibition Computerization for Development-the Research Challenge, (pages 191198). Kuala Lumpur: Universiti Pertanian Malaysia.

[4] Shortliffe, E. H. (1987). Programs to Support Clinical Decision Making. JAMA. Vol. 258, Issue 1 pages 61-67. American Medical Association.

[5] Szolovits, P.,Doyle, J.,Long, W. J., Kohane, I. and Pauker. S. G. (1994). Guardian Angel: Patient-Centered Health Information Systems. TR-604, Massachusetts Institute of Technology, Laboratory for Computer Science, 545 Technology Square, Cambridge, MA, 02139.

[6] Shortliffe, E. H. (1998). The Evaluation of Health-Care Records in the Era of the Internet. http://smiweb.stanford.edu/pubs/abstracts_by_author/

[7] Rusovick, R., Warner, D, (1997). The Webification of Medicine: Interventional Informatics through the WWW. http://www.pulsar.org/febweb/papers/mwww3.htm Sarle. Journal of the American Medical Association.

[8] Chellappa, M. (1995). Telemedic-Care. NCIT'95: 8'th National Conference Information Technology'95 (1618). Gabungan Komputer Nasional Malaysia.

[9] Warner, D. (1997). Malaysian Medical Matrix: Telemedicine in the age of the Multimedia.

[10] Djam, X. Y., Wajiga, G. M., Kimbi, Y. H. and Blamah, N. V. (2011). A Fuzzy Expert System for the Management of Malaria. International Journal of Pure and Applied Sciences and Technology. 5(2), 84-108.

[11] Donfack, A. F., Abdullahi, M., Ezugwu, A. E. and Alkali, S. A. (2009). Online system for Diagnosis and Treatment of Malaria.

[12] Adekoya, A. F., Akinwale, A. T. and Oke, O. E. (2008). A Medical Expert System for Managing Tropical Diseases. Proceedings of the Third Conference on Science and National Development. 74-86.

[13] Obot, O. U. and Uzoka, F. M. E. (2008). Fuzzy RuleBased Framework for the Management of Tropical Diseases. International Journal of Engineering and Informatics, 1(1), 7-17.

[14] Djam, X. Y. and Kimbi, Y. H. (2011). Fuzzy Expert System for the Management of Hypertension. The Pacific Journal of Science and Technology. 12(1), 390402.

[15] Djam, X. Y. and Kimbi, Y. H. (2011). A Decision Support System for Tuberculosis Diagnosis. The Pacific Journal of Science and Technology. 12(2), 410-425. http://www.akamaiuniversity.us/PJST.htm.

[16] Agboizebeta, I. A. and Chukwuyeni, O. J. (2012). Application of Neuro-fuzzy Expert System for the Probe and Prognosis of Thyroid Disorder. International Journal of Fuzzy logic Systems (IJFLS), 2 (2), 1-11.

[17] Kandel, A. (1991). Fuzzy Expert Systems CRC Press ISBN: 084934297x.
[18] Sugeno, M. and Kang, E. T. (1988). Structure Identification of Fuzzy model. Fuzzy Sets and Systems. $28,15-33$

[19] Takagi T. and Sugeno M. (1985). Fuzzy Identification of Systems and its Application in Modeling and Control. IEEE Transactions on Systems, Man and Cybernetics, $15,116-132$.

[20] Kosko, B. (1991). Neural networks and fuzzy systems: a dynamical systems approach. Prentice Hall. Upper Saddle River. NJ.

[21] Mamdani, E. H. \& Assilian, S. (1975). An experiment in linguistic synthesis with a fuzzy logic controller. International Journal of Man-Machine Studies. 7(1), 113 .

[22] Lee, C. -C (1990) (a). Fuzzy logic in Control Systems: Fuzzy Logic Controller - Part I. IEEE Transactions on Systems, Man and Cybernetics, 20(2), 404-418.

[23] Lee, C. -C (1990) (b). Fuzzy logic in Control Systems: fuzzy Logic Controller- Part 2. IEEE Transactions on Systems, Man and Cybernetics. 20(2), 419-435.

[24] Jang, J-S. R (1991)c. Self-learning fuzzy controller based on temporal back-propagation. IEEE Transaction on neural network, 3, 714-723.

[25] Jang, J-S. R. (1993)a. ANFIS: Adaptive network based fuzzy inference systems. IEEE Transaction on Systems, Man, and Cybernetics, 23, 665-685.

[26] Jang, J-S. R, (1993)b. Predicting chaotic time series with fuzzy if then rules. In Proceedings of IEEE International Conference on Fuzzy System. San Francisco.

[27] Wang, M. Q. and Hirschberg, J. (1992). Automatic classification of intonational phrasing boundaries. Computer Speech and Language, 6(2):175-196.

[28] Horikawa, S.., Furuhashi, T. and Uchikawa, Y. (1992), On fuzzy modelling using fuzzy neural networks with the back-propagation algorithm, IEEE Trans. Neural Networks, 3(5), pp.801-806,

[29] Hinton, G. E. (1989). Connectionist Learning Procedures. Artificial Intelligence, 40(1), 143-150.

[30] Kosko, B. (1990), Stability and Adaptation of Neural Networks. Published by PN

[31] Rumelhart, D. E., Hinton, G. E. and Willians, R. J. (1986). Learning internal representations by error propagation. In D.E, Rumelhart and James L. McClelland, editors, parallel distributed processing: explorations in the microstructure of cognition, volumes 1, chapter 8, pages 318-362. MIT Press, Cambridge, MA.

[32] Moody, J. and Darken C. J. (1989). Fast Learning in Networks of Locally-tuned Processing units. Neural Computation, 1, 281-294.

[33] Huang, W. Y. and Lippmann R. P. (1988). Neural Net and Traditional Classifiers in Neural Information Processing Systems. New York: American Institute of Physics, 387-396.

[34] Oladele T. O., Sadiku J. S. and Oladele R. O. (2014), Coactive Neuro-Fuzzy Expert System: A Framework for Diagnosis of Malaria. African Journal of Computing \& 
ICTs (AJOCICT). A Publication of the Computer Chapter of the Institute of Electrical \& Electronics Engineers (IEEE) Nigeria Section. . Vol. 7 No. 2. pp 173 - 186. ISSN: 2006-1781.

[35] Zadeh, L. A. (1965). Fuzzy Sets. Information and Control, 8, $338-35$.

[36] Hopgood, A. A. (1993). Knowledge-Based Systems for Engineers and Scientists. CRC Press. ISBN 0-84938616-0.

[37] Jang, J-S. R. (1991), Fuzzy modeling using generalized neural networks and Kalman filter algorithm. In Proceedings National Conference on Artificial Intelligence (AAAI-91), pp.762-767.

[38] Jang, J-S. R. (1991)b. A self-learning fuzzy controller with application to automobile tracking problem. In Proceedings IEEE Roundtable Discussion on fuzzy and neural systems, and vehicle application. Tokyo, Japan, Institute of Industrial Science, University of Tokyo. Paper no. 10.

[39] Jang, J-S. R., and Gulley N. (1995). MATLAB Fuzzy Logic Toolbox User's Guide. Version 1. The Mathworks, Incorporated.

[40] Jang, J-S. R., Sun, C.T. and Mizutani, E. (1997). Neurofuzzy and Soft Computing (A Computational Approach to Learning and Machine Intelligence), Prentice Hall, Inc. pp1-90.

[41] Kandel, A. (1992). Fuzzy Expert Systems. CRC Press, Inc. Boca Raton, Fl.

[42] Kim, C-H., and Lee, J. (2003). Adaptive Network-based fuzzy Inference Systems with Prunning. SICE Annual Conference in Fukui: Fukui University, Japan.

[43] Klir, G. J. and Yuan B. (1995). Fuzzy Sets and Fuzzy logic. Theory and Practice. Prentice Hall. ISBN 0-13101171-5.

[44] Kulikowski, C. A. and Weiss, S. M. (1982). Representation of Expert Knowledge for Consultation: The CASNET and EXPERT Projects. In Szolovits, P. (Ed.) Artificial Intelligence in Medicine. Westview Press, Boulder, Colorado.

[45] Kumar, Y. and Jain Y. (2012). Research aspects of expert system. International Journal of Computing \& Business Research. ISSN (online); 2229-6166. Proceedings of' Isociety 2012 at GKU, Talwandi Sabo Bathinda, Punjab.

[46] Lin, C-T., and Lee C.S.G. (1991). Neural-Network-based Fuzzy logic control and Decision system. IEEE Transactions on Computers. 40(12).

[47] Mehdi, N. and Mehdi Y. (2009). Designing a Fuzzy Expert System of Diagnosing the Hepatitis-B Intensity Rate and Comparing it with Adaptive Neural Network fuzzy system. Proceedings of the World Congress on Engineering and Computer Science, Vol. II WCECS 2009, San Francisco, USA.

[48] Miller III, W. T., Sutton, R. S. and Werbos, P. J. eds. (1990). Neural Networks for Control. MIT Press.
[49] Mizutani, E. and Jang, J-S. R, (1995). Coactive neural fuzzy modeling. IEEE International conference on Neural Network (ICNN'95).

[50] Mizutani, E. Jang, J-S, R. and Nishio, K. (1995). Coactive Neuro-fuzzy modeling for color recipe prediction.

[51] Pomerleau, D. A. (1991). Efficient training of artificial neural networks for autonomous navigation. Neural Computation, 3, 88-97.

[52] Pomerleau, D. A. (1992). Neural network perception for mobile robot guidance. PhD. Thesis, Department of Computer Science, Carnegie Mellon University.

[53] Poole, D., Mackworth, A. and Goebel, R. (1996). Computational Intelligence: A Logical Approach, Oxford University Press. ISBN 0-19-510270-3.

[54] Psaltis, D., Sideris, A. and Yamamura, A. (1988). A mutilayered neural Network controller. IEEE Control Systems Magazine. 8(4), 17-21.

[55] Sivanandam, S. N. and Deepa, S. N. (2007). Principles of Soft Computing, Wiley India (P) Ltd.

[56] Sivanandam, S. N., Sumathi, S. and Deepa, S. N. (2007). Introduction to Fuzzy logic using MATLAB. Springer.

[57] Sugeno, M., editor (1985). Industrial applications of fuzzy control. Elsevier Science.

[58] Tek, F. B., Dempster, A. G. and Kale, I. (2009). Computer Vision for Microscopy Diagnosis of Malaria. Malaria Journal. 8,153.

[59] Tsoukalas, L.H. and Uhrig, R.E. (1993). Fuzzy and Neural approaches to Engineering. John Wiley \& Son, Inc.

[60] Werbos, P.J. (1991). An overview of neural network for control. IEEE Control Systems Magazine, 11(1), 40-41.

[61] Yasunobu, S. and Miyamoto, S. (1985). Automatic train operation by predictive fuzzy control. In M. Sugeno, editor, Industrial applications of fuzzy control, pages 118. North-Holland, Armsterdam.

[62] Zadeh, L. A. (1973). Outline of a New Approach to the Analysis of Complex Systems and Decision Processes. IEEE Transaction Systems, Man and Cybernetics. 3(1), $28-44$.

[63] [63] Zilouchian, A and Jamshidi, M,. (2001). Intelligent Control Systems using Soft Computing Methodologies. CRC Press. ISBN 0-8493-1875-0.

[64] http://www.aptronix.com/fuzzynet/app/note/reactor.htm.

[65] http://www.controleng.com/, Temperature Control: PID Vs fuzzy logic.

[66] http://www.fuzy-logic.com fuzzy logic tutorial.

[67] Super Coridor

[68] http://www.pulsar.org/febweb/papers/m3web.htm.

[69] http://www.audubondentalcare.com/index.php?option=co m_content \&view=article \&id=82\&Itemid=62.

[70] http://dentistry.about.com/od/toothmouthconditions/Dent al_Problems_Conditions_and_Diseases.htm 
International Journal of Applied Information Systems (IJAIS) - ISSN : 2249-0868

Foundation of Computer Science FCS, New York, USA

Volume 8-No.2, January 2015 -www.ijais.org

[71] http://www.groups.csail.mit.edu/medg/ftp/psz/AIM82/ch 1.html.

[72] http://healthinformatics.wikispaces.com/Artificial+Intelli gence+in+Medicine.

[73] http://library.thinkquest.org/05aug/00109/medicine.htm

[74] http://www.medicinenet.com/gum_problems/article.htm

[75] http://www.namibiadent.com/History/HistoryDentistry.ht $\mathrm{ml}$.
[76] http://www.openclinical.org/aiinmedicine.html

[77] http://en.wikipedia.org/wiki/Dental_software

[78] http://en.wikipedia.org

[79] Tooth Erosion.jpg, http://www.lookfordiagnosis.com

[80] Padlock.png, http://www.becuo.com 